\title{
Modelling Snowmelt Runoff Using an Artificial Neural Network (ANN) Approach
}

\author{
Reşat Acar, Serkan Şenocak, Semet Çelik
}

\begin{abstract}
The use of artificial neural networks (ANNs) is becoming increasingly common in the analysis of hydrology and water resources problems. In this research, an ANN was developed and used to model the snowmelt runoff, in a catchment located in a semiarid climate in Turkey. The multilayer perceptron (MLP) neural network was chosen for use in the current study. The one year data (2009) obtained from the stations, located in Erzurum Kırkgöze (Çipak) basin, are integrated into daily average time series of temperature (T), solar radiation $(\mathbf{R})$, snow-covered area $(S)$, snow water equivalent (SWE), runoff coefficient for snow (Cs).
\end{abstract}

The results indicate that the artificial neural network method is suitable to predict the river discharges by using some variables and parameters of snowmelt for the Kirkgöze Basin.

Keywords - Artificial Neural Network, Modelling, Snowmelt Runoff Model, Turkey

\section{Introduction}

Artificial Neural Networks (ANNs) provide advantages over conventional hydrological models by successfully identifying the nonlinear hydrologic relationship between input output parameters. They are also adaptable to changing circumstances, which provides improved model performance, shorter calculation times and faster model development. Due to the advantages of ANNs mentioned above, ANNs have been widely used in hydrological applications during the last two decades.

In many areas of the world, snow accumulation and subsequent melt are the most critical determining factors for producing an adequate water supply. This research aims to develop an snowmelt runoff model by using ANN method in the snow dominated and mountainous Kırkgöze (Çipak) basin.

\section{Methodology}

\section{A. Study Area}

The Kırkgöze basin, a sub-basin of the upper Euphrates basin, is located in the eastern part of Turkey (Figure 1). The Kırkgöze basin has mountainous and forestless area. The basin has a drainage area of $242.52 \mathrm{~km}^{2}$ with an elevation ranging from 1823 to 3140 meters [1].

Reşat Acar (Co-Author), Serkan Şenocak, Semet Çelik

Atatürk University / Civil Engineering Department

Turkey

racar@atauni.edu.tr

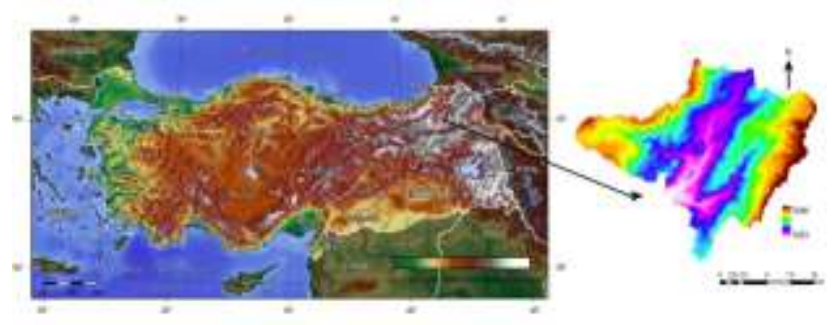

Figure 1. Map of study area [1].

\section{B. Data}

It is shown that the sufficient and qualified climate data can be collected in a real time from three stations, having different aspects and altitudes, in a mountainous basin with high snow potential in Kırkgöze (Çipak) basin [2]. Variables and parameters that is used to predict the discharge by ANN is calculated from the three automatic meteorological stations in conjunction with remote sensing and geographic information systems.

The data obtained from the stations are integrated into daily average time series of temperature (T), solar radiation (R) and snow water equivalent (SWE). The other parameters, snow-covered area (SCA), runoff coefficient for snow (Cs), are calculated by using remote sensing and geographic information systems.

The most common meteorological data collected anywhere are of air temperature. Ideally, these measurements should be made at a specified height above the snow surface, shielded from the effects of radiation or conduction from sources other than the atmosphere

Radiation is the only form of energy transfer that can be measured directly in the natural environment. Greatest use of radiometers in hydrology is in the studies related with evaporation and snowmelt.

Snow water equivalent (SWE), which is actually the multiplication of snow density and snow depth, is an important characteristic of snow.

It is a typical feature of mountain basins that the areal extent of the seasonal snow cover gradually decreases during the snowmelt season. MODIS and NOAA images are currently operated for generation snow cover areas (S).

Runoff Coefficients are used to determine losses which are differences between available water volumes and the sum of snowmelt. 


\section{Artificial Neural Networks (ANNs)}

The ANN technology is an alternate computational approach inspired by studies of the brain and nervous systems. It is based on theories of the massive interconnection and parallel processing architecture of biological neural systems. The main theme of ANN research focuses on modeling of the brain as a parallel computational device for various computational tasks that were performed poorly by traditional serial computers.

In the present study, the multilayer perception (MLP) trained with a back propagation algorithm is used to predict the discharge values. The MLP consists of two input layer consisting of node(s) representing various input variable(s), the hidden layer consisting of many hidden nodes, and an output layer consisting of output variable(s). The input nodes pass on the input signal values to the nodes in the hidden layer unprocessed. The values are distributed to all the nodes in the hidden layer depending on the connection weights $\mathrm{W}_{\mathrm{ij}}$ and $\mathrm{W}_{\mathrm{jk}}$ between the input node and the hidden nodes $[3,4,5]$. Connection weights are the interconnecting links between the neurons in successive layers. Each neuron in a certain layer is connected to every single neuron in the next layer by links having an appropriate and an adjustable connection weight.

The architecture of the neural network used in this study and the schematic representation of a neuron are shown in Figure 2 .

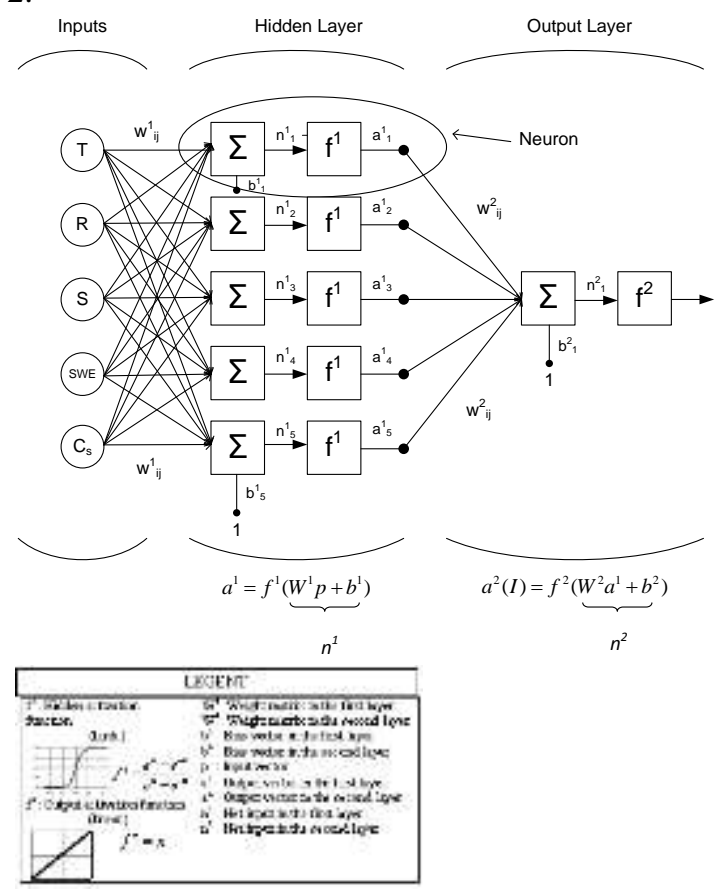

Figure. 2. Architecture of the neural network model used in this study.

In this study, both statistical and graphical criteria were adopted to select the desired optimal network model. The statistical criteria consist of average squared of error (ASE), coefficient of determination $\left(\mathrm{R}^{2}\right)$ and the mean absolute relative error (MARE). They are given by

$$
\begin{gathered}
A S E=\frac{\sum_{i=1}^{N}\left(I t_{i}-\widehat{I} t_{i}\right)^{2}}{N} \\
R^{2}=1-\frac{\sum_{i=1}^{N}\left(I t_{i}-\widehat{I} t_{i}\right)^{2}}{\sum_{i=1}^{N}\left(\left(I t_{i}-\bar{I}_{i}\right)^{2}\right.} \\
\text { MARE }=\frac{\left.\sum_{i=1}^{N} \mid\left(\widehat{I I}_{i}-I t_{i}\right) / I t_{i}\right) \mid}{N}
\end{gathered}
$$

where $I t_{i}$ and $\hat{I t}_{i}$ are respectively, the actual and predicted value of discharges (normalized between 0 and 1), $\bar{I} t_{i}$ is the mean of $I t_{i}$ values and $\mathrm{N}$ is the total number of data sets. The $\mathrm{R}^{2}$ statistic measures the linear correlation between the actual and predicted discharges values.

The ASE and MARE statistic measures are used to quantify the error between observed and predicted values. The optimal value for $\mathrm{R}^{2}$ is equal to 1.0 and for ASE and MARE is equal to 0.0 . The graphical performance indicator gives better results when the data pairs are closing to $45^{\circ}$ line and the good superposition between the desired and calculated flow values in the training and testing phases.

For the data set considered in the present study, the input variables as well as the target variables are first normalized linearly in the range of 0 and 1 . The main reason for standardizing the data matrix is that the variables are usually measured in different units. By standardizing the variables and recasting them in dimensionless units, the arbitrary effect of similarity between objects is removed.

\section{Results}

The database compiled represents predicted discharge values for Kırkgöze (Çipak) basin. In this study, the data are used for the any 13 days for model testing, while the other remaining data any 52 days was used for model training/ verification. The training phase of ANN model was terminated when the average squared error (ASE) on the testing databases was minimal. The goal of the training process is to reach an optimal solution based on some performance measurements such as ASE, coefficient of determination known as R-square value $\left(R^{2}\right)$, and the MARE. Therefore, required ANN model was developed in two phases: training phase, and testing (generalization or validation) phase.

In the training phase, a larger part for database (52 days) was used to train the network and the remaining part of the database is used in the testing phase and verification. Testing sets are usually used to select the best performing network model. In this research, the ANN was optimal at 700 iterations with 5 hidden nodes. The corresponding accuracy measures of this network model on testing and training data are given in the following table (Table 1). Generally, accuracy measures on training data are better than those on testing data.

The comparison between the predicted and actual flow values at training and testing phases show excellent agreement 
with the $\mathrm{R}^{2}$ are respectively 0.951718 and 0,977878 (Figure 3 and Figure 4). Note that, data pairs closer to the $45^{\circ}$ line represent better prediction cases. The good performance and convergence of the model are illustrated in Figure 3.

TABLE I. STATISTICAL PARAMETERS OF PREDICTED AND ACTUAL DISCHARGE AT TRAINING AND TESTING PHASES

\begin{tabular}{|c|c|c|c|c|}
\hline \multirow{2}{*}{$\begin{array}{c}\text { Statistical } \\
\text { Parameters }\end{array}$} & \multicolumn{2}{|c|}{ Training Phase } & \multicolumn{2}{c|}{ Testing Phase } \\
\cline { 2 - 5 } & $\begin{array}{c}\text { Actual } \\
\text { Discharge } \\
\mathrm{m}^{3} / \mathrm{s}\end{array}$ & $\begin{array}{c}\text { Predicted } \\
\text { Discharge } \\
\mathrm{m}^{3} / \mathrm{s}\end{array}$ & $\begin{array}{c}\text { Actual } \\
\text { Dischar } \\
\mathrm{ge}^{3} / \mathrm{s}\end{array}$ & $\begin{array}{c}\text { Predicted } \\
\text { Discharge } \\
\mathrm{m}^{3} / \mathrm{s}\end{array}$ \\
\hline Average & 6.9852 & 6.9859 & 5.5223 & 6.2563 \\
\hline $\begin{array}{c}\text { Standard of } \\
\text { deviation }\end{array}$ & 3.2295 & 3.0758 & 2.8363 & 2.6164 \\
\hline Minimum & 2.05 & 3.27 & 1.55 & 2.7918 \\
\hline Maximum & 13.4 & 14.14 & 13,0 & 12.799 \\
\hline ASE & 0.98284 & & 0.85835 & \\
\hline $\mathrm{R}^{2}$ & 0.90580 & & 0.95620 & \\
\hline MARE & 0.14589 & & 0.20744 & \\
\hline
\end{tabular}

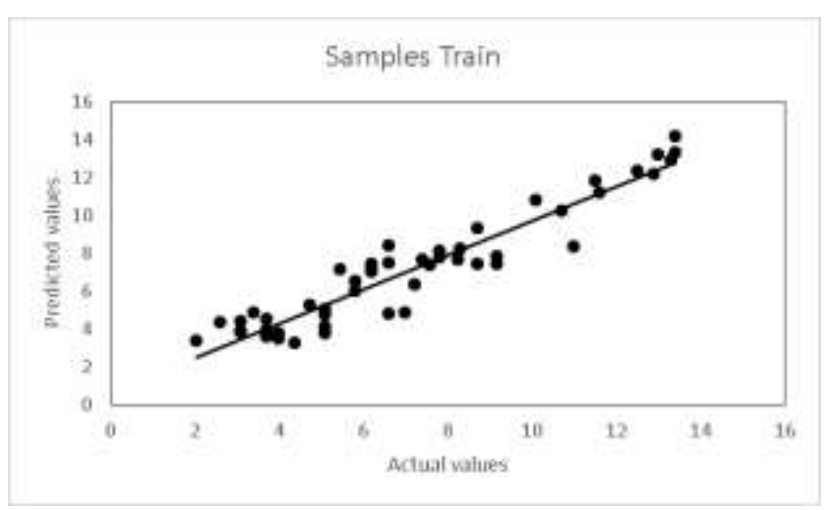

Figure 3. Comparison between the actual and ANN predicted discharge values at training phase.

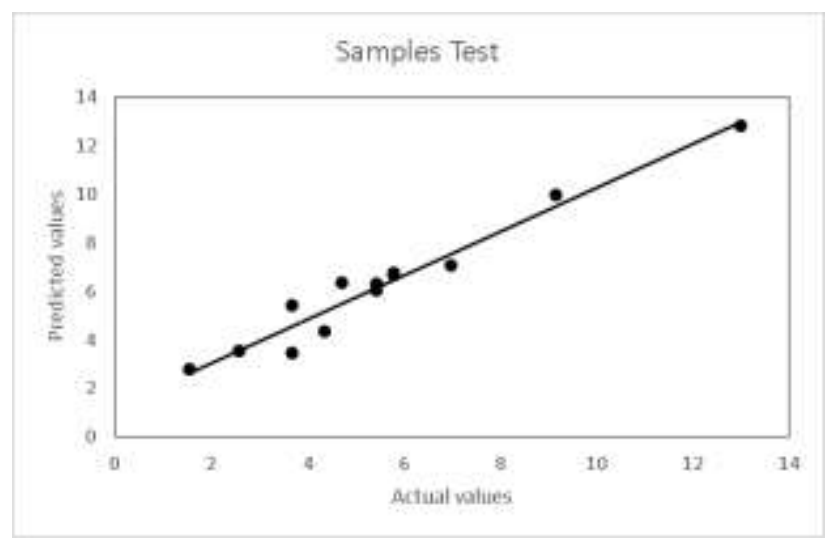

Figure 4. Comparison between the actual and ANN predicted discharge values at testing phase.

\section{Conclusion}

The artificial neural network (ANN) models show good capability to model hydrological process. The results indicate that the artificial neural network (ANN) method is suitable to predict the river discharges by using some variables and parameters of snowmelt for the Kırkgöze Basin. They are useful and powerful tools to handle complex problems compared with the other traditional models. The ANN approach could provide a very useful and accurate tool to solve problems in water resources studies and management.

\section{Acknowledgment}

This project is funded by The Scientific and Technological Research Council of Turkey (TUBITAK 106Y293).

\section{References}

[1] S. Şenocak, "Application of Snowmelt Runoff Model (SRM) in conjunction with using both Geographical Information Systems and Remote Sensing Techniques for mountainousrRegions and a case study of Erzurum-Kirkgoze Basin," Ph.D. dissertation, The Graduate School of Natural and Applied Sciences of Atatürk University, Erzurum, Turkey, 2011.

[2] A. Acar, S. Şenocak and S. Şengül, S., "Snow Hydrology Studies in the Mountainous Eastern Part of Turkey." The IEEM International Conference on Industrial Engineering and Engineering Management, Hong Kong, China, 1578-1582, 2009.

[3] Y. Najjar and H. Ali, "CPT-based liquefaction potential assessment: A neuronet approach," ASCE Geotechnical Special Publication, 75, 542553, 1998.

[4] Y. Najjar and H. Ali, "On the use of BPNN in liquefaction potential assessment tasks," Artificial Intelligence and Mathematical Methods in Pavement and Geomechanical Systems, 55-63, 1998.

[5] Y. Najjar and X. Zhang, "Characterizing the 3D stress-strain behavior of sandy soils: A neuro-mechanistic approach," ASCE Geotechnical Special Publication, 96, 43-57, 2000. 